Programa de Pós-Graduação em Engenharia de Produção - PPGEP
Laboratório de Qualidade de Vida - LaQVida
Universidade Tecnológica Federal do Paraná - UTFPR
Ponta Grossa - PR - Brasil
v. 04, n. . 20, jul./dez. 2012, p. 50-56

DOI: $10.3895 / \mathrm{S} 2175-08582012000200005$

\title{
Entrevista realizada com Ana Magnólia Bezerra Mendes
}

\author{
Camila Lopes Ferreira \\ Instituto Federal do Paraná - IFPR - Paranaguá - Brasil \\ camila.ferreira@ifpr.edu.br \\ Luiz Alberto Pilatti \\ Universidade Tecnológica Federal do Paraná - UTFPR - Ponta Grossa - Brasil \\ lapilatti@utfpr.edu.br
}

\begin{abstract}
Ana Magnólia Bezerra Mendes é Professora do Departamento de Psicologia Social e do Trabalho e do Programa de Pós-graduação em Psicologia Social e do Trabalho e das Organizações (PSTO) do Instituto de Psicologia da Universidade de Brasília (UnB). Tem pós-doutorado no Conservatoire National des Arts et Métiers (CNAM), Paris, doutorado em Psicologia pela UnB e sanduíche na Universidade de Bath, Inglaterra, mestrado e graduação em Psicologia.

É coordenadora do Laboratório de Psicodinâmica e Clínica do Trabalho, onde orienta teses, dissertações e monografias nas temáticas: organização do trabalho, prazer-sofrimento e saúde; estratégias de mediação do sofrimento; patologias e adoecimento psíquico; violência no trabalho; práticas em clínica psicodinâmica do trabalho.

Também é Pesquisadora do CNPq desde 1996, além de Coordenadora do GT Psicodinâmica e Clínica do Trabalho na Associação Nacional de Pesquisa e Pós-graduação em Psicologia (ANPEPP).
\end{abstract}

Ressalta-se que foi mantida a entrevista na íntegra, visando preservar a originalidade do depoimento gentilmente oferecido pela entrevistada, a qual agradecemos enormemente de antemão.

\section{Poderia contar um pouco acerca de sua trajetória acadêmica que lhe permitiu grande reconhecimento na área de 'Psicodinâmica do Trabalho'?}

A minha trajetória profissional iniciou quando da conclusão do curso de graduação em psicologia em 1884 na Universidade Federal de Pernambuco. Ainda como estudante decidi pela Psicologia do Trabalho, realizando estágio na área de saúde do trabalhador, quando iniciei meu percurso na leitura das obras de Christophe Dejours, com a publicação do livro "A loucura do trabalho" em 1986 no Brasil.

Em 1991 surgiu a oportunidade de ingressar na Universidade Federal de Pernambuco como professora no departamento de psicologia. Desde então exerço minhas atividades exclusivamente na carreia docente. Desde esta data, me dediquei ao estudo da problemática saúde mental e trabalho, utilizando a abordagem da psicodinâmica do trabalho.

Em 1994 conclui o mestrado na Universidade de Brasília nesta temática. O tema da minha dissertação versou sobre a investigação da influência da organização do trabalho nas vivências de 
prazer-sofrimento do trabalhador qualificado na perspectiva da psicodinâmica do trabalho, considerando estas vivências com expressão da subjetividade e saúde mental no trabalho.

Em 1995 passei a ser professora na Universidade de Brasília, e pesquisadora do CNPq, conclui o doutorado em 1999 na mesma Universidade, estudando esta temática e em 2006 fiz meu pós-doutorado com Christophe Dejours no CNAM em Paris.

Nesta direção minha trajetória na psicodinâmica do trabalho se inicia praticamente com a criação da própria teoria nos anos 80. A consolidação desta trajetória teve início em 2007, em que foi criado o primeiro Laboratório de Psicodinâmica e Clínica do Trabalho, que já funcionava como grupo de pesquisa desde 1995, no Departamento de Psicologia Social e do Trabalho, na Universidade de Brasília. Co-habitou neste mesmo ano com o I Simpósio Brasileiro de Psicodinâmica do Trabalho e o I Curso de Especialização, promovidos pela Universidade de Brasília.

Diversos desdobramentos aconteceram a partir deste ano. O simpósio encontra-se na sua IV versão e em 2009 foi lançado o I Congresso, que já se encontra na III versão. Ao longo destes 20 anos dezenas de dissertações e teses foram orientadas e centenas de publicações, que podem ser consultadas no sistema de currículo lattes do CNPq e no site do laboratório www.lpct.com.br.

Atualmente, coordeno o Grupo de Psicodinâmica e Clínica do Trabalho vinculado á Associação Nacional de Pesquisa e Pós-Graduação em Psicologia (ANPEPP), que reúne 18 pesquisadores de todas as regiões brasileiras, estamos inseridos em redes internacionais de pesquisa e ainda com muitos projetos para dar continuidade a esta expansão da psicodinâmica do trabalho.

\section{Com mais de uma década de estudo, como você avalia as transformações ocorridas no mundo do trabalho? Pode-se dizer que vivemos num cenário novo?}

O trabalho vem se tornando cada vez mais fundamental na vida das pessoas. Essa centralidade traz consequências paradoxais para a integridade física, psíquica e social dos indivíduos. Por um lado, o trabalho - como atividade produtiva ontológica -, constituinte da identidade do trabalhador assume papel essencial para assegurar à saúde; em contrapartida, os contextos nos quais ele se insere levam a uma precarização de condições e oportunidades, contribuindo para um possível adoecimento dos trabalhadores.

Hoje se percebe um trabalhador submisso, que se sujeita e se vê sujeitado pela solidão socialmente produzida pela competitividade exacerbada, pela padronização de condutas, pelo descaso do estado, pela exclusão social, pelo desemprego, pela condição de inempregável, além da intolerância em relação às diferenças individuais e dificuldades diversas em manter e promover o prazer e a saúde no ambiente de trabalho.

Desta forma, percebe-se no atual cenário socioeconômico o descarte da subjetividade. Há supremacia dos processos de padronização, desprovendo a tarefa de sentido.

Ao efetuar a desapropriação do saber do trabalhador, a organização do trabalho promove também a desapropriação à liberdade de criação. A organização do trabalho, ao limitar a participação dos funcionários em decisões e imprevistos que ocorrem no dia a dia, limita-os escrupulosamente à execução das prescrições ditadas. As consequências são uma série de agravos à saúde física e psíquica, como as lesões por esforços repetitivos (LER) e doenças osteomusculares relacionadas ao trabalho (Dorts). Além da dor física relatada, surge a angústia, difícil de ser nomeada no ambiente laboral pela impossibilidade de sua exposição, uma vez que nesse tipo de espaço há impedimento do encontro entre o sujeito portador de uma história singular e personalizada e uma organização do trabalho despersonalizante.

O trabalho está marcado hoje pela patologia da solidão e do desamparo, os trabalhadores encontram-se presos em armadilhas que a gestão gerencialista e da qualidade total impõe. É o uso exagerado do controle, da previsibilidade e da produção. Estratégias altamente sofisticadas são usadas pelos gestores hipermodernos, são legitimadas e reconhecidas pela ciência da racionalidade econômica e instrumental. 
O sujeito é negado, não existe espaço para falhas e para o sofrimento como parte do humano. Se o trabalhador não ocupar uma posição de super-homem é considerado desadaptado. Prevalecem as noções funcionalistas e desubjetivantes, transformando o trabalho num lugar de patologias sociais e de adoecimento. Em nome das normas, do produtivismo e da busca frenética por reconhecimento (narcisista), o comportamento perverso da sociopatia começa a ser comum no mundo das organizações.

O rompimento de vínculos de relações fundamentais para manutenção e fortalecimento da subjetividade humana tem provocado a desmobilização e dessubjetivação, tornando o indivíduo apartado de desejo, descompromissado e dissociado do seu saber-fazer. Nesse contexto, torna-se robotizado, uma ferramenta útil à empresa, negando a falha, podendo desencadear a violência, o assédio moral, o qual tem sido compreendido atualmente como a exposição dos trabalhadores a situações humilhantes e constrangedoras, repetitivas e prolongadas durante a jornada de trabalho; e que passam a ser mais desestabilizadoras.

Mesmo assim, logo as relações ficam mais desumanas e aéticas, nas quais predominam os desmandos, a manipulação do medo, a competitividade desenfreada e os programas de qualidade total associados à produtividade e dissociados do prazer, do saudável e do sentido humano do trabalho.

\section{Em sua opinião, quais são as perspectivas futuras do mundo do trabalho?}

O mundo do trabalho torna-se, de forma rápida e surpreendente, um complexo monstruoso, patrocinado pelos que mantêm o controle do capital, da ferramenta diária que movimenta a escolha de prioridades, avassala o indivíduo em todos os seus aspectos. Alguns são absorvidos, exigidos, sugados. Outros alçados a postos de poder e de liderança que reproduzem o capital virtual. Outros, por assim dizer, alguns milhões, são jogados como a escória que a água benta do emprego, da possibilidade do trabalho, não veio a salvar.

Esse princípio de realidade adentra e fere o psiquismo humano, fazendo com que as pessoas sintam-se exigidas; o sentimento de impotência e de desvalorização, que leva as pouco resistentes a degenerar-se rapidamente, avilta de si qualquer potencial humano que pudesse se somar às conquistas da civilização.

É preciso reconhecer o sofrimento, elaborar, perlaborar e deliberar, a saída para estas armadilhas é se apropriar dos destinos deste sofrimento, buscando proximidade com a emancipação, é sair da alienação.

Nesta perspectiva, trabalhar é fracassar, trabalhar é sofrer. Este real vai se revelar ao sujeito pela impotência. Assim, o sofrimento no trabalho se dá pelo insucesso de se distanciar das prescrições, que são na maior parte das vezes ideais inatingíveis, correspondendo a um modelo de perfeição ditado pelos modos de gestão das organizações trabalhistas.

Este distanciamento inevitável gera muitas adversidades para os trabalhadores, que estão destinados a fracassar, sendo esta a razão das dificuldades de obter a normalidade. Logo, a conquista é constante porque a perfeição não existe e a própria morte denuncia tal limitação. Não serão os manuais de procedimentos que darão conta de controlar as imperfeições, falhas e faltas do humano. Não existe possibilidade de o trabalho real, vivo, corresponder às prescrições em função do que é imprevisível, inédito, especialmente porque é um sujeito que faz, e que irá se deparar com uma série de situações imprevistas para resolver.

\section{Há uma reclamação, mais ou menos geral e permanente, dos trabalhadores sobre as suas condições de trabalho. Qual a sua opinião?}

Estas condições são reflexos de um modelo gerencial desumanizado e produtivista. Os indicadores desta situação são observados nas seguintes práticas gerenciais: gestão pelo controle, 
medo, pressão, desconfiança e insegurança legitimada e estimulada pela cultura organizacional, normas sem limites ou muito padronizadas, poder autocrático ou permissivo, comunicação sem visibilidade, paradoxal e restrita, foco exagerado na produção, metas inatingíveis, falta de sentido do trabalho, sistema de avaliação inadequado gerando individualismo, competição e clima de rivalidade, desestruturação do coletivo e a patologia da solidão.

Os modos de gestão que contribuem para as vivências de sofrimento são o mau uso do poder, que potencializa atitudes autoritárias e desconsidera a capacidade física de execução dos trabalhadores. Mudanças ocorrem sem o esclarecimento do processo, gerando incerteza e insegurança quanto ao futuro profissional. A descontinuidade de ações definidas no planejamento gera medo e estresse no ambiente profissional, uma vez que projetos criados e em fase de implantação podem ser descartados, e com eles toda a identidade e empenho profissional de quem que os executou. Faltam feedback e participação dos trabalhadores nas decisões sobre a tarefa desempenhada.

Os dilemas entre fazer bem e fazer mais, entre cooperar e sobrecarregar-se e silenciar e denunciar as injustiças, leva os trabalhadores a um sofrimento patogênico e adoecimento. As condições de trabalho é um destes efeitos da precarização, exigências e intensificação do trabalho, além da dinâmica de negação do sujeito e interdição da palavra.

\section{Como pesquisadora, qual é a sua percepção em relação às contribuições que a área da psicodinâmica do trabalho tem dado ao desenvolvimento das atividades no âmbito organizacional?}

Estamos cada vez mais vivenciando no trabalho a interdição da palavra, a ausência dos espaços públicos da discussão e dos coletivos de trabalho. Uma das maiores contribuições da psicodinâmica é a clínica do trabalho, que promove o espaço de fala para o sujeito e, ao mesmo tempo, busca intervir no discurso, dando condições de ressignificar vivências, dar novos sentidos e refletir em um nível de consciência diferente.

$\mathrm{O}$ ato de ceder esse espaço traz grandes mudanças, seja pela oportunidade de repensar, seja pela sensação de ser escutado por um outro que se posiciona de maneira aberta para realizar essa escuta, para interagir e discutir o que foi vivido pelo sujeito quando em contato com o trabalho, além de discutir como as outras dimensões de sua atividade estão interferindo e contribuindo para seu desempenho e também para seu processo de saúde-adoecimento.

Na dimensão do coletivo os efeitos da clínica do trabalho estão articulados ao fortalecimento do coletivo, possibilitando a construção de novos recursos para mediar o sofrimento. Nas práticas apresentadas, percebe-se uma conexão entre o coletivo de pesquisa, um momento para se perceber o componente invisível do trabalho do outro, um momento de feedback e reconhecimento.

Esse processo de fortalecimento do coletivo cria o espaço necessário para que as defesas sejam desconstruídas e os trabalhadores possam se engajar, por meio do reconhecimento e da cooperação, em sistemas defensivos mais saudáveis.

O resultado das práticas clínicas que temos desenvolvido, tantos na empresas como nos sindicatos, foi utilizado como base para programar mudanças de gestão a partir do diagnóstico dado. A criação de espaços para a fala e discussão aliados às novas habilidades de escuta tornam-se potencialmente positivos para se criar um novo modo de gestão efetivo, com a participação de todos e um senso de pertencimento que permite o trabalhador continuar se engajando. Esses novos modos criados a partir da análise clínica do trabalho mostram a importância e o reconhecimento que a organização dá aos que ali trabalham, permitindo que todos se vejam um pouco na própria estrutura da organização.

No campo político, a clínica do trabalho tem contribuido para qualificar pesquisas que se baseiam em dados estritamente numéricos, desconsiderando dos estudos o sofrimento psíquico, e orientar a criação de políticas públicas preventivas para os adoecimentos em diversas categorias profissionais. 
O sujeito se torna protagonista à medida que as ações propostas resultam de experiências vividas e assumidas, diferente de uma assumir uma postura alienada e oprimida que se submete às tarefas prescritas tal como as recebe. Os modelos gerais são questionados e, diante do inesperado na execução do trabalho diário e considerando o nível da subjetividade dos indivíduos e dos grupos, podem surgir novas atitudes, novas sensibilidades, novas práxis.

O importante nesse trabalho é colocar o trabalhador em cena, tirando-o de uma relação de dependência, uma relação infantilizada, na qual a mudança deve vir de fora, na qual a culpa é sempre do outro e a solução é idealizada. É fundamental captar o campo de possíveis no trabalho real, questionar como o grupo se engaja para alcançar as mudanças que necessita. Caso contrário, ficarão esperando o Estado ou a Empresa trazer a solução. Motivar as pessoas em seu desejo de mudança é uma das tarefas do clínico do trabalho.

A função da clínica é desmontar os aspectos infantis e queixosos das falas, que se revelam por projeções, negações, racionalizações. São atos que saem da generalidade para nomear o afeto das pessoas e de suas experiências, propiciando que desempenhem um papel em uma dinâmica positiva.

A política, dessa forma, sai de uma lógica programática para uma lógica das diferentes classes de trabalhadores e situações. A questão social passa a ser formulada em um espaço público, fortalecendo a postura do engajamento coletivo. Ela denuncia aos sujeitos a solução ideal e torna a realidade aceitável.

Por fim, é importante ressaltar as questões éticas envolvidas na clínica. A ética na clínica do trabalho situa-se no respeito às diferenças dos sujeitos envolvidos. Busca-se a interpretação das defesas coletivas sem fazer dela um ato de violência, já que desnudar o sofrimento e a dimensão subjetiva pode ocasionar sérias consequências aos trabalhadores.

Busca-se uma fala verdadeira e a realização, pelo sujeito, de sua história em relação a um futuro, diminuindo o abismo do reconhecimento entre seu afeto e a emissão das suas palavras.

Ao partir do princípio de que os sujeitos sofrem e manifestam seu sofrimento, a ética do clínico do trabalho é assegurar a discrição e o sigilo, permitindo ao trabalhador identificar, nomear e comunicar determinadas percepções avaliadas como ameaça. A verbalização do sofrimento deve ser ancorada pelo grupo por meio do laço que se forma com os envolvidos e propiciar ao sujeito potência para modificar o lugar que ocupa. O reconhecimento pelo outro da situação que gera malestar é essencial para a confrontação com o real experimentado e o que coloca o sujeito em movimento.

O reconhecimento é fundamental para a formação da vontade e concretiza a cooperação. A cooperação está na base coletiva do trabalho, sendo fundamental para construir a obra comum. Às vezes, o objeto construído é invisível, pois não aparece de forma objetiva e clara, ocasionando a paralisia, tornando a palavra interditada em algumas sessões.

Nessa situação, o clínico atua apontando o sintoma para mudança, elaborando, com o grupo, os sentimentos invisíveis, desnudando os cenários prescritos e repetitivos para possibilitar o confronto com o real, manifestado no silêncio e que denega o sujeito da sua realidade.

A busca pelo prazer e saúde nesses encontros está centrada na plasticidade para viver outras experimentações, questionar relações e, por meio das falas plurais, não determinar um só comportamento, um a priori saudável, mas ser capaz de incorporar elementos novos e diferentes, desmitificando o ideário de vencer o sofrimento e a infelicidade.

\section{Conflito é uma perspectiva central dentro da psicodinâmica do trabalho. Gostaria que a senhora relacionasse o conflito com a Qualidade de Vida no Trabalho, um tema em voga no mundo do trabalho.}

Qualidade de vida no trabalho é vivenciar sofrimento criativo e prazer. O prazer para abordagem científica da Psicodinâmica do Trabalho não é uma relação direta. É construção intersubjetiva que integra o psíquico e o social de modo indissociável, no trabalhar, no fazer, na 
expressão da subjetividade, no coletivo de trabalho e nos modos como as relações de trabalho se constroem, produzindo um jogo de forças e uma dinâmica própria aos contextos de trabalho.

Esta dinâmica não está descolada dos efeitos da acumulação flexível do capital sobre os modelos gerencialistas de gestão. Está regida pela lógica da racionalidade econômica, principal fonte inspiradora para as novas formas de organização do trabalho, que por sua vez, criam novas formas de subjetivação, de sofrimento, de patologias e de possibilidades de reação e ação dos trabalhadores.

Considerado este contexto, a Psicodinâmica insere-se no campo das teorias críticas do trabalho, mas, sobretudo, é uma teoria clínica. Tem como objeto central compreender a mobilização subjetiva no trabalho, que é o engajamento afetivo mediado pelo uso da palavra que o trabalhar, o trabalho vivo produzido pela organização do trabalho, nas contradições entre o prescrito e o efetivo, exige do trabalhador. Neste processo, é imprescindível compreender o sofrimento como o afeto que mobiliza os investimentos do indivíduo para transformar a organização do trabalho. Quando esta transformação é possível o prazer é vivenciado.

Trabalhar significa enfrentar o real que é imprevisível, imprevisto, incontrolável, instável. Este real coloca em xeque as prescrições visíveis e invisíveis da organização do trabalho. No real do trabalho o sujeito, se mobiliza para a ação, busca colocar em prática o que pensa sobre o seu fazer, torna o seu trabalho vivo.

Nesta direção, a mobilização subjetiva para o trabalhar provoca uma desestabilização dos afetos, por isso um sofrimento, denominado de criativo. Este sofrimento move o trabalhador a buscar soluções para as dificuldades do seu trabalho e quando consegue encontrá-las vivencia gratificação e prazer. Assim, a mobilização subjetiva é vivenciar sofrimento criativo e prazer no trabalho.

Ao contrário, a mobilização pode levar a paralisação frente ao real quando envolve angústia, medo e insegurança, transformando o sofrimento criativo em sofrimento patogênico. Torna-se patogênico quando não é exteriorizado, quando o sujeito é negado, a palavra é interditada, imobilizando-o, uma vez que não tem mais espaço para se expressar, discutir sobre o fracasso, a dor e a impotência. É o sofrimento não ressignificado que mantém o trabalhador queixoso, paralisado, sem ação sobre o real.

Este sofrimento patogênico tem se intensificado diante das novas formas de organização do trabalho, que revelam um modo de dominação social muito mais sofisticado e difícil de ser identificado. A flexibilização do capital tem levado a precarização e a um sofrimento ético, marcado pela banalização das injustiças e do mal, ocasionando, o surgimento de patologias sociais. Diante desse contexto, o sofrimento se apresenta como uma reação, uma manifestação da resistência e da insistência em viver em ambiente precarizado, funcionando assim, como um mobilizador para luta contra as patologias sociais.

Esta luta é mantida pelo uso de estratégias de defesa. Diante das novas formas de organização do trabalho, diferentes tipos de defesa individuais e coletivas vêm sendo construídas pelos trabalhadores. Destacam-se como exemplos: a aceleração, o individualismo, a banalização, o cinismo, dissimulação, hiperatividade, desesperança de ser reconhecido, desprezo, infligir danos aos subordinados, negação do risco inerente ao trabalho e distorção da comunicação. Funcionam como uma 'anestesia', que permite ignorar o sofrimento patogênico e negar suas causas. Ao mesmo tempo, leva a criação de um obstáculo à capacidade do trabalhador de pensar sobre o seu trabalho, de agir e de lutar contra os efeitos deletérios da organização do trabalho, sobre sua subjetividade, sua saúde e qualidade de vida no trabalho.

Quando se instala este processo de anestesia e atinge o coletivo de trabalho, considera-se que a luta foi perdida e em seu lugar instalam-se as patologias sociais, uma delas é a violência e seus desdobramentos como o assédio moral. $\mathrm{O}$ assédio é assim uma experiência coletiva produzida pelas falhas das defesas frente ao sofrimento patogênico gerado na angustia, medo e insegurança diante da interdição da mobilização subjetiva exigida no confronto com o real do trabalho.

Neste contexto, é inexistente a qualidade de vida no trabalho. Para vivenciá-la, a luta contra o sofrimento patogênico precisa ser vencida e a mobilização subjetiva operar em toda sua potência. 
A mobilização subjetiva é composta por dimensões indissociáveis como a inteligência prática, o espaço de discussão, a cooperação e o reconhecimento. Não depende da vontade do trabalhador. Emerge quando os trabalhadores agem de forma a subverter os efeitos prejudiciais da organização do trabalho. É uma mobilização, sobretudo, política.

Viabiliza a dinâmica do reconhecimento, um modo específico de retribuição simbólica dada ao sujeito, como compensação por sua contribuição aos processos da organização do trabalho, pelo engajamento da subjetividade e da inteligência. Prescinde para tal, do coletivo de trabalho construído pelos trabalhadores. Seus elementos constitutivos são: solidariedade, confiança, cooperação e pressupõe a existência de um espaço público da fala e da promessa de equidade quanto ao julgamento do outro.

O trabalhador se mobiliza e se engaja no trabalho pelo seu poder negociando, pressionando e se apropriando ou rejeitando as regras do coletivo de trabalho. Sua ação inscreve-se sobre uma dinâmica de troca que tem por efeito garantir a consecução dos seus objetivos e do coletivo de trabalho. Desse modo, para que o trabalho seja fonte de qualidade de vida é central a mobilização das condições políticas capazes de levá-lo a mobilização da inteligência prática, do espaço de discussão, da cooperação e do reconhecimento no trabalho possibilitando o sofrimento criativo e o prazer. 